\title{
LAS MUJERES CUIDADORAS INMIGRANTES: UN ANÁLISIS EN DATOS DE 1992 - 2009 POR EL MUNDO, EN ESPECIAL SOBRE LA REALIDAD DE ESPAÑA
}

\author{
IMMIGRANT WOMEN CAREGIVERS: AN ANALYSIS IN DATA FROM 1992 - 2009 AROUND \\ THE WORLD, ESPECIALLY THE REALITY OF SPAIN
}

Douglas Verbicaro Soares

Universidade Federal de Roraima, Boa Vista, RR, Brasil. E-mail: douglas_verbicaro@yahoo.com.br

DOI: https://doi.org/10.46550/amormundi.v2i2.50

Recebido em: 23.12.2020

Aceito em: 23.02.2021

\begin{abstract}
Resumen: El estudio tiene como objetivo visualizar la realidad de las mujeres inmigrantes en los ámbitos laboral, social y colectivo, centrándose en el tema de la discriminación de género, influenciada por factores histórico-culturales. Muchos de ellos transmitidos a lo largo de los siglos, por un modelo patriarcal de sumisión femenina en diferentes sociedades. La investigación abordará el tema de las mujeres, destacando el factor humano en el desempeño de la actividad laboral femenina de la atención, especialmente en el contexto español. Se llevó a cabo una investigación bibliográfica y documental como procedimiento metodológico, utilizando el enfoque cualitativo y cuantitativo. La investigación tiene una investigación bibliográfica multidisciplinar, como historia, ciencias jurídicas y etc. Esta investigación concluye por la existencia de discriminación para las mujeres en el desempeño de la actividad laboral, razón por la cual se necesitan más estudios para visualizar estos problemas para el cambio de paradigma.
\end{abstract}

Palabras clave: Discriminación. Género. Igualdad. Inclusión Social.

Abstract: The study aims to visualize the reality of immigrant women in the labor, social and collective spheres, focusing on the issue of gender discrimination influenced by historical-cultural factors. Many of them transmitted over the centuries, by a patriarchal model of female submission in different societies. The investigation will work with the theme of women highlighting the human factor in the performance of female labor activity of care, especially in the Spanish context. A bibliographic and documentary investigation was carried out as a methodological procedure, using the qualitative and quantitative approach. The research has a multidisciplinary bibliographic investigation, such as history, legal sciences and etc. This research concludes by the existence of discrimination for women in the performance of work activity, which is why further studies are needed to visualize these problems for paradigm shift.

Keywords: Discrimination. Gender. Equality. Social Inclusion.

\section{Introducción}

$\triangle$ ntes de hablar sobre las mujeres inmigrantes cuidadoras, es importante hacer una Abreve introducción sobre el derecho al trabajo como un derecho social. En este sentido, en las Constituciones de distintos países, los derechos sociales salen del capítulo: orden 
social. Los derechos sociales son prestaciones positivas proporcionadas por el Estado, tanto de modo directo o indirecto, previstas en normas constitucionales (VERBICARO SOARES, 2012, p. 21).

Por este motivo, debe considerarse el trabajo no como una obligación, pero sí un derecho, es decir: él está presente en el ámbito de los derechos económicos y sociales, justificado en el hecho de que todos los seres humanos tienen el derecho de sobrevivir y de decidir de modo libre una profesión, siendo el trabajo escogido supuestamente satisfactorio y sobretodo equitativo.

La esencia de que el derecho al trabajo es un derecho social tiene base internacional. La Declaración Universal de los Derechos Humanos, en su artículo 23, expresa que:

Toda persona tiene derecho al trabajo, a la libre opción de escoger un empleo, a condiciones justas y favorables de trabajo y a la protección contra el desempleo. Todas las personas, sin cualquier tipo de discriminación, tienen derecho a la igual remuneración por igual trabajo. Todas las personas que trabajan tienen derecho a una remuneración justa y satisfactoria, que les asegure, así como a su familia, una existencia compatible con la dignidad humana (BRASIL, 2012).

En este sentido, la Declaración establece su esencia para el ejercicio de los derechos laborales. En Brasil, la Constitución Federal (CF) de 1988, materializa el contenido de la Declaración Universal de Derechos Humanos, dándole una garantía legal, pero que cabe al Estado tornarlo efectivo. En su artículo $6^{\circ}$, trata el trabajo como un derecho social (a través de él que el hombre puede obtener las condiciones materiales - económicas, para su propia manutención). Además, en sus artículos siguientes: del $7^{\circ}$ al $11^{\circ}$, la CF refuerza sus ideas sobre esos derechos, reconociéndolos como sociales (BRASIL, 2020). Es importante recordar que esa Carta Magna de Brasil no ha sido la primera en reconocer ese ideario en América. México ha sido novedoso en 1917, entendiendo que estos derechos serían esenciales a la organización de aquel Estado.

Por más que la Constitución Federal de Brasil reconozca la labor como un derecho social, no existe actualmente en la legislación, ningún medio eficaz que trate de garantizar que ese trabajo pueda ser ejercido. De hecho, no se puede negar la existencia de medidas que busquen atenuar la situación de muchos ciudadanos que no encuentran trabajo. De todos los modos, aún no ha sido suficiente para permitir su ingreso en el trabajo o de tener una mejora en su condición de vida, de un trato más igual entre todos.

En contrapartida, en España por ejemplo, los preceptos semejantes están previstos en el artículo 35 de la Constitución de 1978: Todos los españoles tienen el deber de trabajar y el derecho al trabajo, a la libre elección de profesión u oficio, a la promoción a través del trabajo a una remuneración suficiente para satisfacer sus necesidades y las de su familia, sin que en ningún caso pueda hacerse discriminación por razón de sexo (CONGRESO, 2003). Lo que demuestra esfuerzos de los constituyentes en la elaboración de instrumentos de protección del trabajo en el Reino de España.

Para la investigación ha sido empleada una metodología basada en fuente bibliográfica multidisciplinar, con relación con el derecho, la historia, etcétera. El estudio tiene cinco (5) apartados, más la introducción, consideraciones finales y referencias.

De ese modo han sido realizadas algunas preguntas para el estudio: ¿Cómo es la situación histórica de las mujeres? ¿Habrá división sexual en el trabajo? ¿Cómo esa división está relacionada 
con la inmigración? ¿Cuál es la condición de la mujer inmigrante? ¿Cómo es el mercado de trabajo del cuidado?

\section{Breve histórico de la situación de las mujeres en el mundo}

En las sociedades: Egipcia, Griega, Mesopotámica, las mismas limitaban la participación de la mujer en sociedad en el cuidado del hogar y de los hijos, incluso de otras personas, sin que se les permitiesen participar en los negocios públicos. En la edad media, las mujeres asumían todas las obligaciones domésticas de su propio hogar, complementándolo con el cuidado de los demás (de familiares o terceros). En la edad moderna, ellas siguieron circunscribiéndose en el ámbito de los trabajos domésticos, es decir: un espacio doméstico feminizado y de menor importancia social, siendo invisibles socialmente, con una característica de inferior relevancia. Como se la condición de nascer mujer estaría relacionada con el hecho de la supuesta justificación de sumisión y dependencia al sexo masculino (VERBICARO SOARES, 2012, p. 22).

Para Masanet e Baeninger, sobre las mujeres brasileńas inmigrantes indocumentadas, recuerdan que el servicio doméstico constituye la puerta de entrada en el mercado de trabajo en España, y también, la principal fuente de renta inicial. Así, el ingreso laboral de las mujeres brasileñas ocurre generalmente en el servicio doméstico con las tareas propias del hogar y del cuidado. Después de un tiempo en ésta actividad, las mujeres cambian de empleo, pero siguen en el mismo tipo de actividad, dentro del mercado secundario, de menor valor y prestigio social (MASANET; BAENINGER, 2011, p. 68).

Cuando se habla de los derechos de las mujeres, es importante hacer referencia a la historia del ingreso femenino en el mercado de trabajo, evaluando desde la división del trabajo en las sociedades primitivas hasta la actualidad. Para que se pueda comprender los orígenes y la propia lógica que ha generado los caminos seguidos, más actualmente por la grande mayoría de las sociedades contemporáneas.

En este sentido, se entiende que la posición de las mujeres en una situación de verdadera desigualdad en las esferas sociales, políticas, económicas y culturales, donde se manifiesta la sumisión femenina en relación a los hombres. Es válido argumentar que la desigualdad generada a lo largo de la propia evolución histórica de la humanidad ha sido justificada como siendo supuestamente natural, como cierta y, además, una estructura que estaría imposibilitada de sufrir cambios esenciales, lo que ha generado todavía más situaciones de desigualdades entre hombres y mujeres.

De este modo se nota, claramente, la existencia de todo un mecanismo de división entre los sexos, principalmente sobre el cuidado y trabajo doméstico, una vez que siguen en estos sectores la mayoritaria participación de las mujeres. Hechos que representan todo un resultado negativo para las mismas, pues impiden su visibilidad en el ámbito público y trato igual con los hombres. De esta forma, interiorizando el femenino a una idea de inexistencia de poder decidir, es decir, que no tienen supuestamente fuerza para tomar el mando y tienen que sujetarse a las tareas del cuidado y del hogar. La definición más tradicional del cuidado relacionase directamente con el trabajo relacionado por las mujeres, como vocacional y natural (CORTEZ, 2008).

Cambiar esta realidad solamente será posible con una concientización general de la sociedad, donde los hombres, detentores de una forma de dominación más amplia, puedan 
"aceptar" que las mujeres tengan su efectiva participación en los más diversos sectores citados supra en igualdad de condiciones (VERBICARO, 2009, p. 25) Esto es lo que enfatiza el ideal feminista: no existe la superioridad de la figura de la mujer en relación al hombre y sí igual participación entre ambos (GONZÁLEZ BUSTOS, 2006, p. 3-4).

Es curioso notar que en la actualidad, las mujeres efectivamente salen al mercado de trabajo, pero muchas lo hacen para vincularse nuevamente al ámbito doméstico, lugar que les fue asignado históricamente (SOARES, 2008, p. 05). Tanto es cierto que las mujeres salen al mercado de trabajo como "breadwinner", es decir: en la situación de única o como la principal fuente de renta para la familia, con el dinero recibido por su trabajo es invertido en casa con los nińos, sea en el mantenimiento y sustento de la familia, o en la construcción de casa o reforma, incluso en financiar estudios para los niños; o aportando un salario complementario en la economía familiar (ya que el salario principal lo aportaría en este caso su esposo en un contexto heteronormativo dominante).

\section{La división sexual del trabajo en el ámbito doméstico y actividades de cuidado}

Cuanto a esa cuestión, podemos citar la existencia de todo un modelo estructural de trabajo doméstico, que se aplica también en las tareas del cuidado, dirigidas a las mujeres (nacionales o inmigrantes), es decir: un modelo patriarcal, corporativista, que dificulta que las mujeres puedan desarrollar sus vidas en el medio público de la sociedad. Por esta razón, ellas se ven obligadas a ocupar los puestos que se les permiten, los que están relacionados, en general, con los cuidados de la casa y de la familia (CONSCIENCIA FEMINISTA, 2011).

Con base en esos argumentos se nota la presencia de ideas estereotipadas antiguas, es decir, de valores culturales más conservadores ¿Por qué no decir machistas? Que justifican erróneamente que las mujeres han sido siempre las responsables en sociedad en desarrollar este tipo de trabajos dentro de casa, en los espacios privados. De este modo, ya tienen una cierta predisposición para realizar esta tarea, de manera que es visto por la propia sociedad como algo normal del trabajo femenino (SOARES, 2008, p. 10).

Con base en esa idea, se nota toda una consolidada fuerza dentro de las propias familias, como también, por el medio (la sociedad) que las direcciona a desarrollar estas actividades como siendo algo normal pasado de generación y generación, como se fuera un plus añadido en sus vidas. En muchos de los casos, las mujeres trabajan realizando las tareas del hogar además de la familia, también trabajan fuera de casa, realizando las mismas actividades y cuidando de otras personas (niños y personas mayores), recibiendo una baja remuneración por la labor realizada (PAZ, 2011). Pertinente es el gráfico a seguir que aborda algunos datos sobre la ocupación laboral femenina en Europa: 


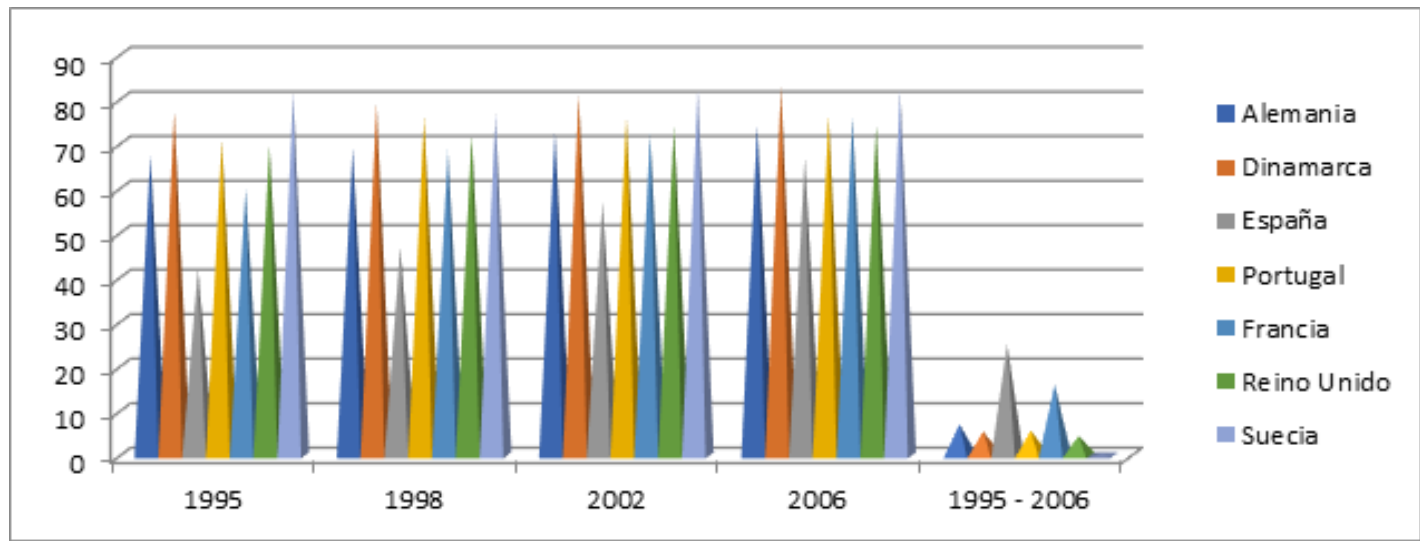

Fuente: La Caixa

El gráfico ejemplifica la incorporación de las mujeres en el mercado laboral, en este caso, enseñando la realidad europea de la ocupación femenina en actividades del ámbito público. Notase en la ejemplificación que los países nórdicos tienen los datos de mayor ocupación femenina, quizás por las políticas de igualdad de trato que vienen aplicando a lo largo de los tiempos entre hombres y mujeres. Así, los datos muestran que Suecia y Dinamarca lideran el ranking con los niveles más elevados en las pirámides, seguidos por Francia, Reino Unido y Portugal.

Percibiese también que dos países tienen destaque en la proyección final de los gráficos, son ellos: España y Francia, una vez que sus datos han sufrido cambios de aumento en la ocupación femenina en el mercado laboral, es decir, que en los años de 1995-2006, ha ocurrido un incremento en el número de mujeres accediendo a actividades en el ámbito público.

Sobre la incorporación femenina en el ámbito público, se han generado nuevas problemáticas, una vez que surgió la necesidad de equilibrar, a partir de la incorporación laboral extra-doméstica, con las tareas del hogar, una disputa por así decir entre el espacio laboral y las obligaciones familiares, buscando lograr compatibilizar las dos actividades, repercutiendo directa y indirectamente en las solicitudes de trabajos con el cuidado de personas y actividades domésticas.

Siguiendo ese raciocinio, los problemas están en la omisión de la participación masculina o de la otra pareja en las actividades del ámbito privado o doméstico, lo que inviabiliza y crea obstáculos para que las mujeres puedan tener una igualdad de trato en las tareas familiares y que puedan salir al mercado laboral.

Lo que ocurre en muchos de los casos es que las mujeres estarían obligadas a optar por la esfera de la familia. En la hipótesis de desarrollar labores fuera, las familias tienen que plantear e invertir en los medios económicos necesarios para la manutención de las tareas indispensables, relacionadas con los servicios de ayuda doméstica, atención y cuidados.

\section{La inmigración}

Parecen oportunas algunas consideraciones sobre las causas que posibilitan o que motivan las migraciones entre los pueblos, sean por motivos sociales, culturales, religiosos, económicos, 
políticos. Causas esas que, de cierto modo, tienen que ver con la motivación de las mujeres inmigrantes cuidadoras en la búsqueda por una situación de vida mejor en otros países. Son válidas algunas ideas encontradas en la obra: el viaje de Laia, como por ejemplo: cambios sociales: acceso de la mujer a la educación, los procesos de urbanización, por la creciente globalización de las comunicaciones y de la información, asi como el cambio de valores están empujando a las mujeres a emigrar (TEN, 2009). Así:

En los últimos años ese incremento ha presenciado cambios una vez que la crisis más actual en España, con variados cortes en prestaciones sociales, con altas tajas de desempleo, o ajustes presupuestarios, por primera vez en los últimos ańos ha disminuido el número de inmigrantes que vienen a buscar mejores condiciones económicas, culturales y sociales (TEN, 2009).

La búsqueda por mejores condiciones de vida y situación, tanto de modo individualizado para las personas que se ponen a inmigrar, como también, pensado en la mejora de la situación de vida de sus familiares (cuestiones económicas). En muchos de los casos buscan su autonomía como persona humana que son, de tener un trato igualitario en sociedad, realización educacional, profesional, escapan de situaciones de calamidades, de violencia religiosa o ideológica, de género o identidad, así como casos de violencia motivada por orientación sexual, sexo, color y raza (TEN, 2009).

El modelo estructural de un país más desarrollado lleva a las mujeres inmigrantes a sectores de participación laboral relacionados a los servicios domésticos, cuidados e personas o al tercero sector de prestación de servicios. Para ejemplificar eses argumentos se hace valida la visibilidad del gráfico a seguir, que trata de algunas de las nacionalidades extranjeras que están afiliadas al régimen de hogar en España.

Imagen 2

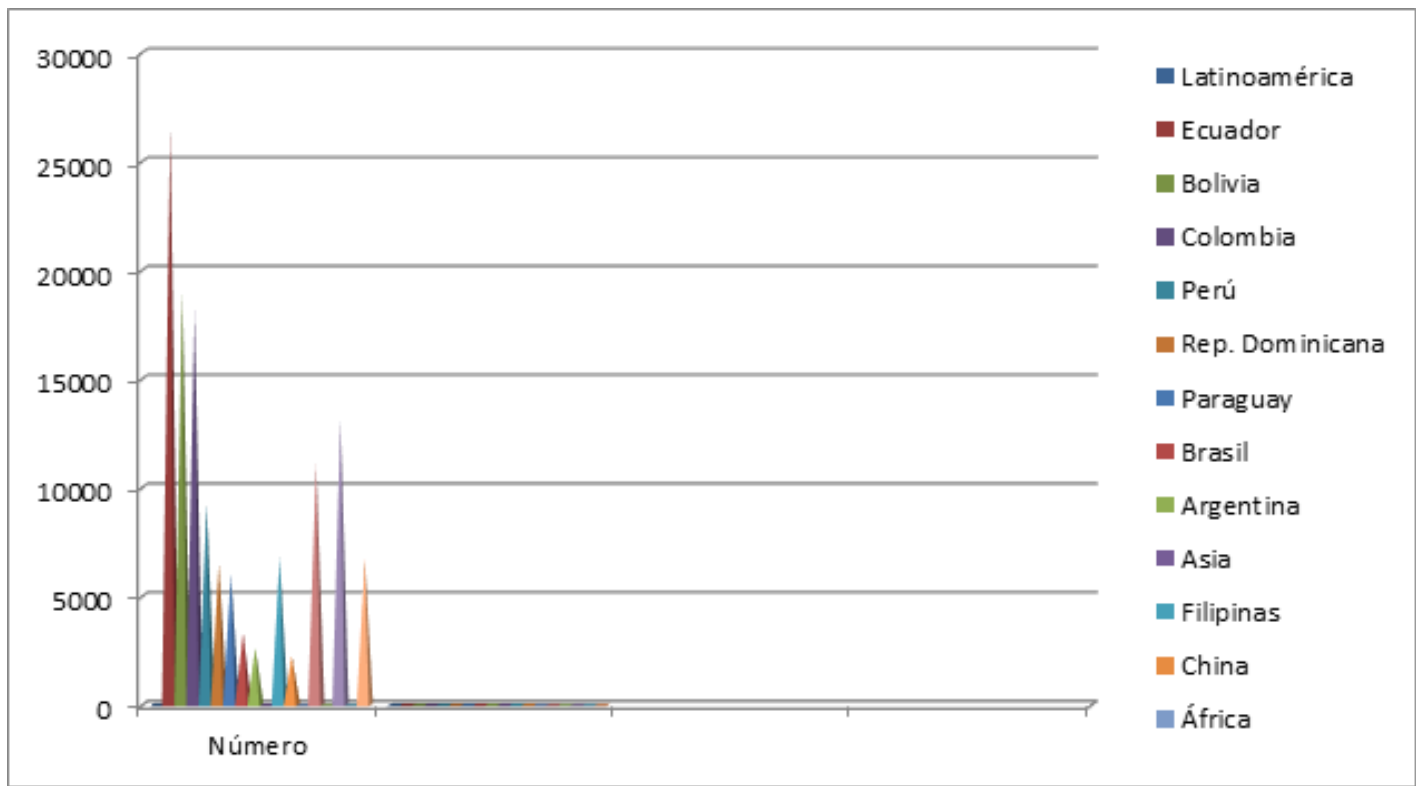

Fuente: La Caixa

El gráfico trabaja con la evolución de los afiliados al régimen de hogar de la seguridad social según nacionalidad. Como podemos notar, la grande mayoría son de procedencia latinoamericana, una vez que factores como el idioma, cuestiones culturales (pues muchos 
países seleccionados en el gráfico son ex colonias españolas), políticos o económicos motivas esa migración de personas hacía España. El número total de latinoamericanos no ha sido disponible para comparar, pero llevando en consideración la cuantidad de personas de países con raíces latinas, se puede tener una idea que es bastante elevado.

Con basa en el material consultado, el porcentual de $65,39 \%$ de todos los inmigrantes que están catastrados es de América Latina. Se trabaja con la idea de que los ecuatorianos, bolivianos y colombianos lideran la filiación en el sistema español, trabajando en actividades del hogar, incluido las de cuidado de personas. En menor proporción están los argentinos y brasileños, que migraran menos, pero que en estos países también reciben otros latinoamericanos en sus territorios, en la búsqueda por mejores condiciones de vida, de trabajo.

De igual forma es pertinente comentar que hay un porcentual significativo de asiáticos que migran hacia Espańa, que pueden llegar a ocupar hasta 6,74\% del número de afiliados al régimen del hogar en la seguridad social española. China tiene menor número registrado de inmigrantes que Filipinas (1,48\% y 4,41\% respectivamente). El continente Africano llega a ocupar un porcentaje de $8,55 \%$ de la cuantidad de inmigrantes en la seguridad social, liderados en el ranking por marroquís, que tiene un porcentaje de 7,24\%, casi la totalidad del número del continente. Europa también envía inmigrantes, es el caso de Rumanía, que no está en el gráfico pero que suma $8,58 \%$, con un número de 13.151 inmigrantes afiliados en la seguridad social en España.

Imagen 3

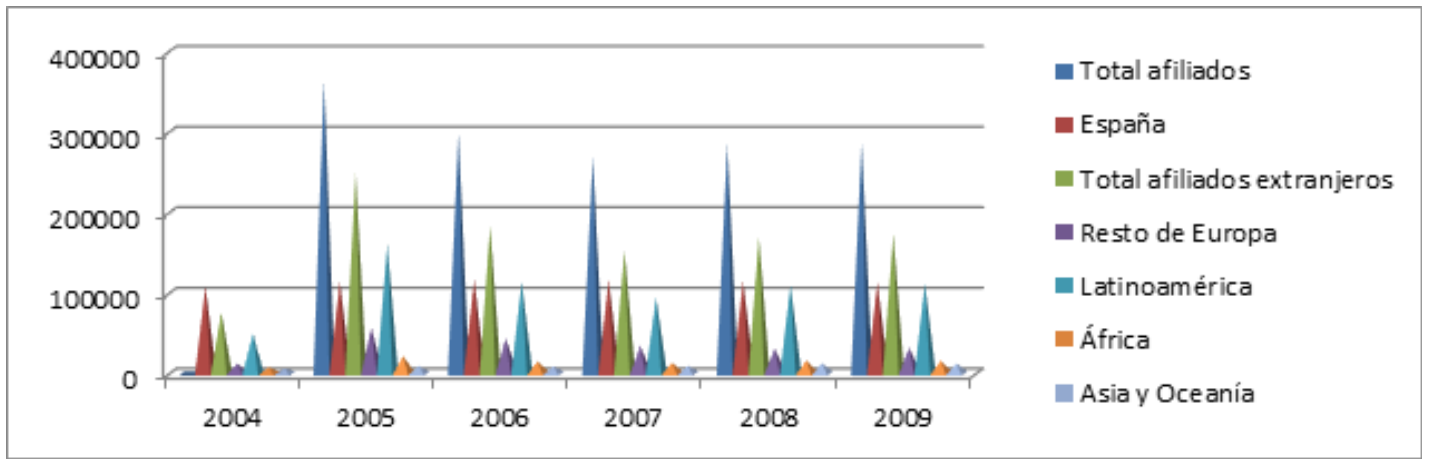

Fuente: La Caixa

Cuanto al gráfico supra, seguimos con una análisis de nacionalidades más general sobre los afiliados en el sistema del hogar registrados en la seguridad social de España, acompañando el desarrollo desde el año de 2004-2009.

El número total de afiliados se ha mantenido casi que estable a su final, es decir, que después de sufrir una diminución en el año de 2006, en relación a 2005, los años siguientes si mantuvieran muy semejantes, finalizando en 2009 con una cantidad de 287.265 personas.

En el caso de los españoles, ellos han presentado reducción en el número de afiliados desde el año de 2008, manteniendo el declive en 2009, con un total de 113.760 afiliados en el hogar. Los afiliados que corresponden al total de extranjeros, en el ańo de 2005 han presentado su ápice, decayendo en 2006 y 2007. En 2008 si recupera y vuelve a subir en 2009, llegando a cifras superiores a 170.000 personas.

En el resto de Europa muestra similitudes al caso anterior, presentando elevación en 
2005, pero los tres años siguientes pasó por declive hasta el año final, logrando 32.471 personas afiliadas.

Para los latinos americanos, el año de 2005 también es el más elevado de afiliaciones, cayendo en 2006 y 2007, volviendo a subir en 2008 y 2009. Igualmente, el continente africano tiene un resultado semejante, aumento en 2005, declive los ańos siguientes y vuelve a aumentar en los dos últimos años, con más de 16.000 personas afiliadas a la seguridad social española en el régimen del hogar.

Asia y Oceanía presentan los niveles más bajos, con un número de 12. 638 afiliados en 2009, datos estos que han presentado aumento en los últimos tres años (2007, 2008 y 2009).

Imagen 4

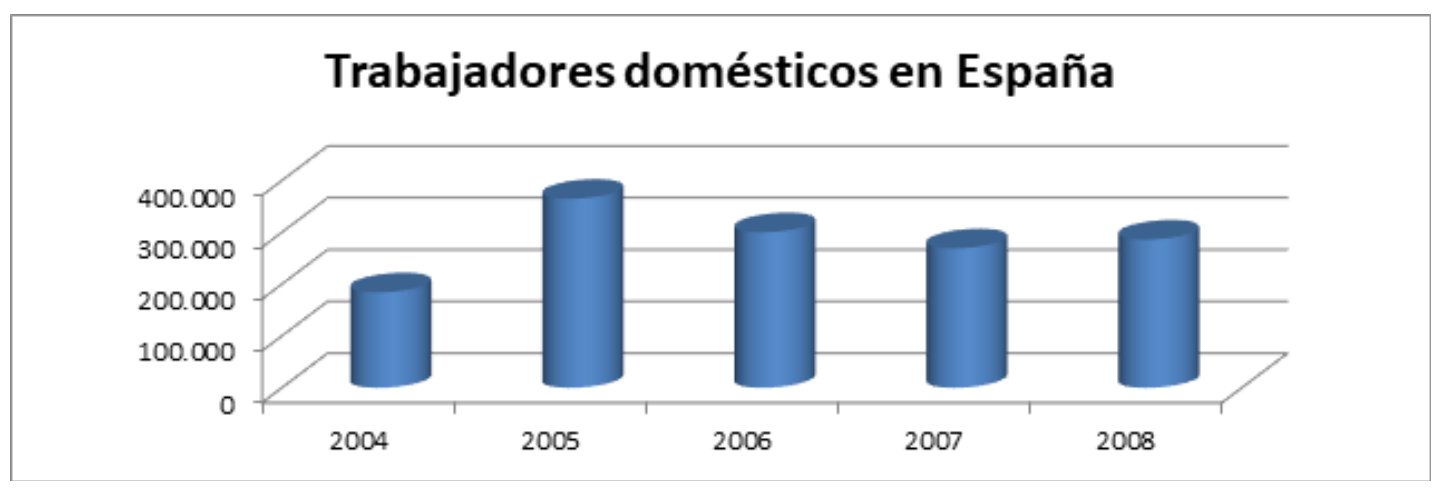

Fuente: La Caixa

Cuanto al gráfico expuesto supra vale comentar que la cantidad de personas inscritas en el régimen del hogar (actividades domésticas y de cuidados) ha sufrido alteración, como se puede notar a partir del año de 2005, debido a la regulación de muchos inmigrantes de su situación legal en el país de acogido (Espańa), lo que ha generado toda una visibilidad de estas personas en el sistema social. Esa situación ha podido sufrir cambios una vez que la crisis, la falta de ofertas de empleos regulados, el regreso de muchos inmigrantes a sus países, la salida de los mismos de Espańa hacía a otros países, el aumento de las ocupaciones de las tareas informales pudieran incidir en una diminución en el control del Estado frente a las actividades de afiliación en la seguridad social española.

De acuerdo con estos parámetros, se hace necesario aclarar que la situación de los trabajadores es mucho más amplia, una vez que hay un grande número de trabajadores que ejecutan sus actividades en el mércalo informal, lo que inviabiliza conocer la real condición de las tareas, tanto por el aparato de la administración pública del Estado español, así como para la sociedad.

\section{La condición de mujer inmigrante}

En el sector del trabajo del cuidado hay una presencia importante de trabajadoras inmigrantes. El acceso al trabajo doméstico y los de cuidado de niños, personas mayores o enfermos, fortalecieron los roles sociales de que las mujeres que deberían desarrollar estas actividades. Para Ten (2009) esa presencia significa un ahorro en la pérdida de tiempo en la búsqueda de empleo y de alojamiento para esas mujeres. Pero además, el acceso que se tiene a esta clase de trabajo se relaciona con la baja cualificación que requiere el mismo: frecuentemente 
a las mujeres inmigrantes les resulta difícil el trámite de reconocimiento de sus títulos, y se imposibilita el trabajar en su propia actividad, acaban sujetándose a trabajar en el empleo que encuentran (TEN, 2009).

Para ellas las pocas ofertas de empleo doméstico y de cuidado que encuentran permiten que las mujeres encuentren un modo se subsistir en el país de acogida.

Para complementar el entendimiento sobre la tasa de empleo femenino en el sector del cuidado (sanidad, atención a mayores, servicios sociales) en menores - aclarador es el primero gráfico, que aborda la situación de las personas menores de 50 años, es decir, con edad de 25-49 años:

Imagen 5

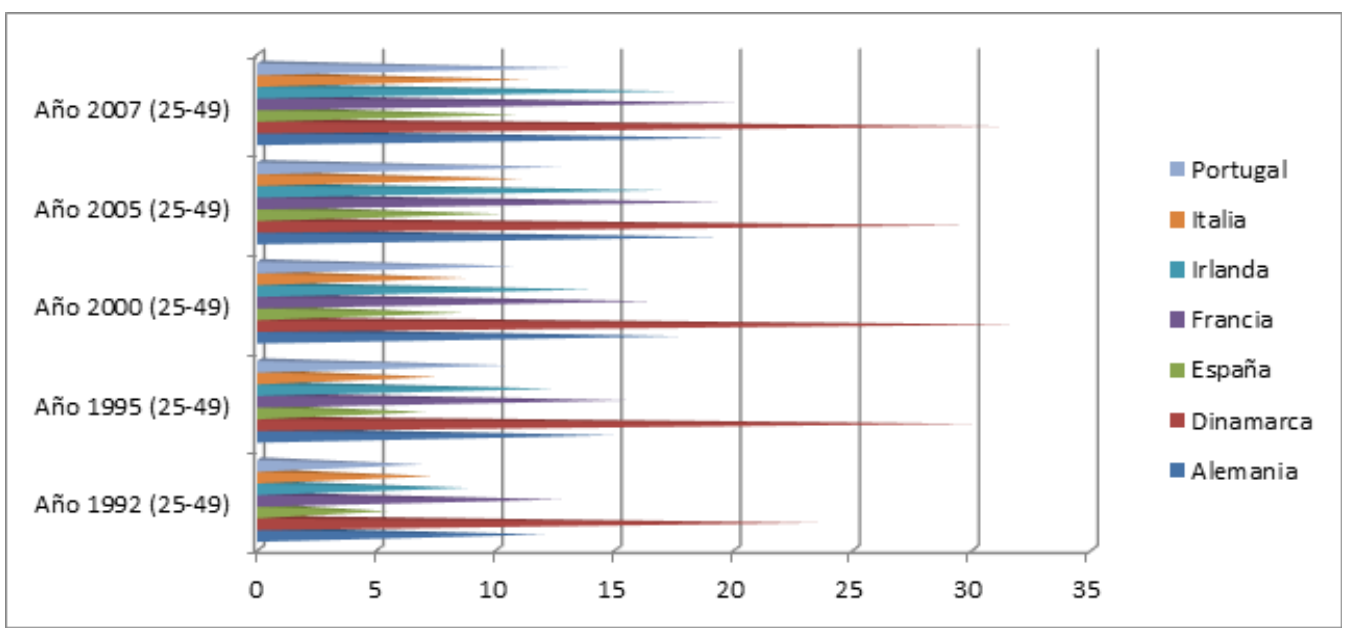

Fuente: La Caixa

El gráfico muestra que en los países como Dinamarca, Alemania, Irlanda, Italia, Francia, Portugal e España han presentado un aumento del empleo femenino de personas edad de 25-49 en el sector del cuidado, sobre todo a partir del ańo de 2000 hasta la fecha final de la pesquisa, que es 2007. Dinamarca despunta desde los primeros años con la mayor cantidad de personas (mujeres) ocupando esa actividad.

En el otro gráfico, que lleva en consideración la edad entre 50-64 años de mujeres en las actividades del cuidado.

Imagen 6

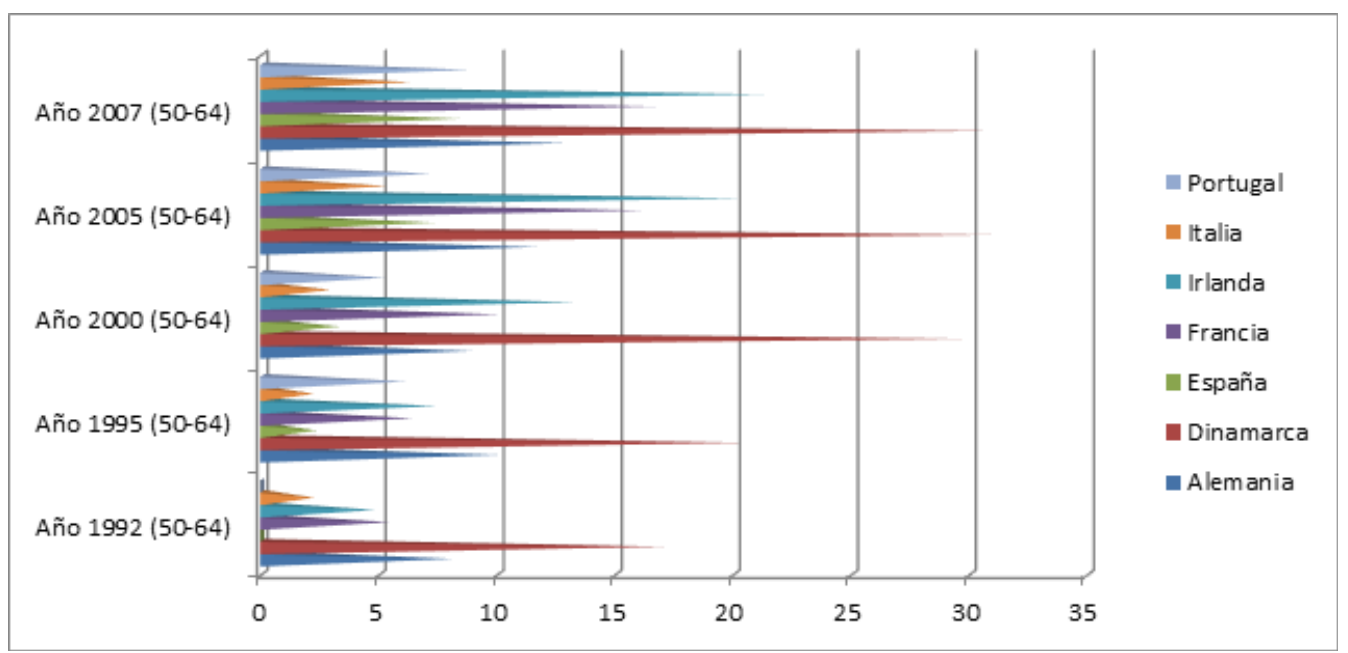

Fuente: La Caixa 
Recordando que esas actividades tienen relación con la sanidad, cuidado a personas mayores y también los servicios sociales. Con base en esas ideas, en España se ha notado un verdadero incremento de la longevidad vital de sus ciudadanos, es decir: se ha aumentado la necesidad de eses servicios debido a un aumento en la expectativa de vida de la población. Pero que todavía están a niveles menores que la ocurrencia en otros país que han experimentado un mayor desarrollo, como ha sido en los casos de los países nórdicos, ejemplo: Dinamarca u otros en Europa, como Alemania, Irlanda o Portugal (que en las últimas décadas han tenido un incremento de estos servicios), visibilizados en el gráfico supra.

Un dato en especial merece ser visibilizado, es la ocupación femenina del segundo gráfico, lo que aborda la edad entre 50-64 años, que enseñan la situación de España, con una inferior participación de las mujeres en esas actividades del cuidado, lo que repercute en la comprensión que esa baja participación de esas mujeres es debida a las tareas que les son atribuidas en el espacio de la propia familia.

Factor que les inviabilizan el mercado de trabajo, en un espacio público, lejos de los atributos domésticos, motivadas por diversas causas, como es el caso de: emancipación personal, complementación del saldo familiar, subsistencia de la trabajadora y de su familia, a aceptar ocupar trabajos en el mercado informal. Hecho que incide de modo negativo tanto en la creación de nuevos y regulares empleos en esa área, así como en un desnivel en las ofertas para la ocupación de ese servicio, generando toda una clandestinidad, baja visibilidad y prestigio social. ¿Qué significa esto? Que muchas mujeres que ocupan eses trabajos son las mujeres inmigrantes, que por factores anteriormente expuestos se someten a los mismos.

\section{El envejecimiento de la población y el mercado de trabajo del cuidado}

El aumento en el envejecimiento de la población y en la demanda por el trabajo del cuidado se ha incrementado en la últimas décadas, relacionándose principalmente con el número de solicitudes para desempeñar los labores relacionados a los cuidados (servicios del hogar, cuidado de terceros - nińos o personas mayores, dependientes) tareas esas que generalmente, en su grande mayoría, ocupadas por las mujeres y mujeres inmigrantes. Además, teniendo relevancia para la manutención del propio modelo de bienestar español (TEN, 2009).

Interesantes son las consideraciones que aducen que las mujeres inmigrantes están siendo utilizadas para sustituir la actividad del cuidado no remunerado: hasta ahora ejercido por las mujeres autóctonas, por un cuidado externalizado en un mercado privado y sin regulación, precario y escasamente profesionalizado (GARCÍA, 2011, p. 04).

No Brasil e nos países de língua espanhola, a palavra "cuidado" é usada para designar a atitude; mas é o verbo "cuidar", designando a ação, que parece traduzir melhor a palavra care. Assim, se é certo que "cuidado", ou "atividade do cuidado", ou mesmo "ocupaçóes relacionadas ao cuidado", como substantivos, foram introduzidos mais recentemente na língua corrente, as noçôes de "cuidar" ou de "tomar conta" têm vários significados, sendo expressóes de uso cotidiano (GUIMARÁES et al., 2011, p. 154).

Es como se fuera un modelo de ayuda y temporario que influí en todo un sistema normativo que tiene que ver con la dependencia, lo que puede repercutir de modo negativo en la formación de un mercado informal del cuidado, movido por personas de otros países que colocan en riego la esencia del modelo de bienestar (GUIMARÁES et al., 2011, p. 154). Por este 
motivo se cobra la viabilidad de regular esa actividad para que esas trabajadoras puedan tener derechos laborales.

\section{Consideraciones finales}

Para finalizar el presente estudio, es interesante recordar que el modelo de familia relacionado con las actividades del cuidado está en crisis, motivado tanto por los cambios de la economía, sociales, políticos y también del modelo de familias. Ese hecho es notado en España, con una característica de familia mediterránea (MORENO, 2001, p. 69), donde todos los integrantes de la familia corroboraban entre sí para la manutención del orden y atender a las necesidades colectivas de sus miembros, motivados por una realidad en que las mujeres salen al mercado laboran y ya no pueden o no están de acuerdo en asumir estos tradicionales labores.

Los motivos expuestos sobre la crisis pueden generar unas grietas de las estructuras del modelo de familia de éste país ibérico, donde anteriormente las relaciones entre los familiares permitían una mayor dedicación de sus propios miembros al cuidado de los demás. Ahora, la situación es diferente, pues España pasa por un proceso de cambio que inviabiliza esa práctica, es decir: las generaciones de mujeres que se encargaban de los cuidados de sus familiares, padres, maridos, hijos nietos se está haciendo mayor y, también, necesitan ser cuidadas.

Hecho ese que choca con el nuevo modelo social, en que las mujeres más jóvenes no aceptan esa imposición social de la conducta estrictamente femenina del cuidado y la salida de las mujeres al mercado de trabajo, rompiendo con el modelo tradicional del "male breadwinner", generando una brecha en la realización y continuidad de la actividad del cuidado, siendo suprimida por la incorporación de la mujer inmigrante, que acepta por su propia situación de vulnerabilidad, de necesidad a ocupar la actividad del trabajo del cuidado, en mucho de los casos, es el único modo de poder subsistir en el país de acogida.

Con esa situación calamitosa, muchos de estos trabajos acaban siendo realizados bajo el manto de la irregularidad, una contratación informal, que no permite en reconocimiento de derechos a las mujeres inmigrantes. Lo que representa una verdadera estafa cuanto a las garantías legales de estas trabajadoras y también para el Estado español que deja de tener beneficios con las contrataciones que podrían ser realizadas, pero que no son.

Es como un círculo vicioso, donde pocos lucran: a) las familias que contractan los servicios irregulares piensan que con la práctica ahorran económicamente que con una contratación regular, no tienen que garantizar derechos de las trabajadoras inmigrantes, pueden estipular los precios a ser pagos por la actividad del cuidado; b) las mujeres inmigrantes sumisas por la situación de estar en otra ciudad, provincia o país están de acuerdo a desarrollar la actividad del cuidado con base en las estipulaciones de las familias contratantes de sus servicios que determinan las reglas, los saldos, los horarios de la actividad; c) con el número mayor de inmigrantes para la ocupar la actividad, cuanto mayor la mano de obra, menor podrá ser la remuneración para la actividad, una vez que no respetan las bases salariares en caso de ser una actividad regular; d) El Estado español pierde por no tener regulada la actividad laboral, deja de recibir la contribución y tampoco puede fiscalizar esas actividades laborales, perdiendo el control sobre esas situaciones que se desarrollan dentro de su propia frontera.

Por esta razón y por los comentarios que han sido realizados en este estudio, es viable 
considerar que la complejidad mencionada sobre las mujeres inmigrantes cuidadoras sirve como motivadora en la labor de descubrir los nuevos rumbos que nortearán esa cuestión, que podrá implicar el auxilio de encontrar maneras para cambiar la realidad actual en Espańa, como en una esfera globalizada.

\section{Referencias}

BRASIL. Constituição da República Federativa do Brasil de 1988. Disponible en: $<$ http://www.planalto.gov.br/ccivil_03/constituicao/constituicao.htm\#: : :text=Art.\%20 6\%C2\%BA\%20S\%C3\%A3o\%20direitos\%20sociais,desamparados\%2C\%20na\%20 forma\%20desta\%20Constitui\%C3\%A7\%C3\%A3o>. Acceso en: 11 mar. 2021.

BRASIL. Declaraçáo Universal dos Direitos Humanos. Disponible en: http://portal.mj.gov. $\mathrm{br} / \mathrm{sedh} / \mathrm{ct} /$ legis_intern/ddh_bib_inter_universal.htm. Acceso en: 11 mar. 2021.

CONGRESO. Artículo 35 de la Constitución española. Disponible en: <https://app. congreso.es/consti/constitucion/indice/titulos/articulos.jsp?ini=35\&tipo=2\#: : :text=Todos\%20 los\%20espa\%C3\%B1oles\%20tienen\%20el,discriminaci\%C3\%B3n\%20por\%20 raz\%C3\%B3n\%20de\%20sexo>. Acceso en: 13 mar. 2021.

\section{CONSCIENCIA FEMINISTA. Os Afazeres Domésticos, Trabalho Doméstico}

Remunerado e a proteçáo do Estado Democrático de Direito. Disponible en: <http:// conscienciafeminista.blogspot.com/2011/05/os-afazeres-domesticos-trabalho.html>. Acceso en: 11 mar. 2021.

CORTEZ, Mariana. Gênero Masculino e a Profissáo do "Cuidar". VI Congresso Português de Sociologia. Mundos Sociais: saberes e práticas. Universidade Nova de Lisboa. Faculdade de Ciências Sociais e Humanas. 25 a 28 de junio de 2008. Lisboa, Portugal.

GARCÍA. Antonio Abellán. INFORMES PORTAL MAYORES: Un perfil de las personas mayores en España. Indicadores estadísticos básicos no 127 de octubre de 2011. España, 2011.

GONZÁLEZ BUSTOS, Ma Ángeles. La Mujer ante el siglo XXI. Una perspectiva desde el ordenamiento jurídico-administrativo. Editora @becedario. Edición primera. Badajoz, Espańa, 2006.

GUIMARÃES, Nadya; HIRATA, Helena; SUGITA, Kurumi. Cuidado e cuidadoras: o trabalho de care no Brasil, França e Japáo. Disponible en: <https://revistappgsa.ifcs.ufrj.br/ wp-content/uploads/2015/01/v1n01_07.pdf>. Acceso en: 11 mar. 2021.

PAZ, María. Economía Feminista. Disponible en: <http:/www.upo.es/congresos/export/sites/ congresos/economiafeminista/documentos/Maria_Florencia_Garcia_Paz.pdf $>$. Acceso en: 11 mar. 2021.

LA CAIXA. Fundación “la Caixa”. Disponible en: <http://obrasocial.lacaixa.es/StaticFiles/ StaticFiles/670e2a8ee75bf210VgnVCM1000000e8cf10aRCRD/es/vol31_es.pdf>. Acceso en: 11 mar. 2021.

MASANET, Erika; BAENINGER, Rosana. Brasileiros e brasileiras na Espanha: mercado de trabalho, seguridade social e desemprego. In: Revista Paranaense De Desenvolvimento. 
Curitiba, n.121, p.65-89, jul./dez. Brasil, 2011.

MORENO, Luis. La vía media española del modelo de bienestar mediterráneo. España, 2001.

SOARES, Daniela Medeiros. Os/As Cuidadores/as dos/as Doentes de Machado-Joseph: uma questáo do Gênero. VI Congresso Português de Sociologia. Mundos Sociais: Saberes e Práticas. Universidad Nova de Lisboa. Portugal, 2008.

TEN. Luz Martínez y otras. El viaje de Laia. Guía de sensibilización sobre la trata de seres humanos con fines de explotación sexual. Instituto de la Mujer. Ministerio de Igualdad. Espańa, 2009.

VERBICARO. Dennis. Consumo e cidadania: da criação à expressáo da solidariedade nas relaçóes de consumo no Brasil. Tesina. Universidad de Salamanca. Curso de Doctorado Pasado y presente de los Derechos Humanos. Salamanca, España, 2009.

VERBICARO SOARES, Douglas. Las mujeres y las personas homosexuales en las Fuerzas Armadas. Especial referencia a las FFAA brasileñas. Trabajo fin de curso Máster Oficial en Estudios Interdisciplinares de Género. Universidad de Salamanca. Salamanca, España, 2012. 